\title{
DIFICULDADES DE CONVIVÊNCIA DO CIDADÃO EM UM PAÍS ONDE REINA A CORRUPÇÃO
}

\author{
Manoel de Jesus Bastos ${ }^{1}$
}

RESUMO: Este trabalho aborda as dificuldades de convivência do cidadão brasileiro em meio à prática da corrupção, observada em quase todos os setores sociais. A situação proporciona inquietação e revolta àqueles que se esforçam a praticar a cidadania. As dificuldades de construí-la e adequá-la, em conformidade com a fonte que lhe outorga, são evidentes, uma vez que convive-se com ações que vão ao desencontro das normativas constitucionais. A prática da cidadania no Brasil está se afunilando, onde os verdadeiros cidadãos sofrem à asfixia democrática por aqueles que praticam atos que contrariam a sociedade. Notadamente, o problema vem ganhando forças ao tempo em que propicia incomodação aos que se empenham a cumprirem com os deveres que lhes estão incumbidos. O principal objetivo deste artigo é explicitar as dificuldades de convivência do cidadão em um país onde apresenta um número espantoso de corrupção. Os resultados pós-pesquisa, despertaram uma intensa inquietação a respeito do assunto e a necessidade de estratégias para o enfrentamento do mesmo. Trata-se de uma pesquisa de cunho bibliográfico com abordagem qualitativa e fundamentada em alguns teóricos, além de algumas fontes oficiais

Palavras-chave: Cidadania. Corrupção. Sociedade brasileira.

ABSTRACT: This work addresses the difficulties of coexistence of Brazilian citizens amidst the practice of corruption, observed in almost all social sectors. The situation causes disquiet and revolt to those who strive to practice citizenship. The difficulties of building and adapting it, in accordance with the source that grants it, are evident, since one lives with actions that go against constitutional norms. The practice of citizenship in Brazil is funneling, where true citizens suffer democratic asphyxia by those who practice acts that go against society. Notably, the problem has been gaining strength at the same time that it causes discomfort to those who strive to fulfill the duties assigned to them. The main objective of this article is to explain the difficulties of the citizen's coexistence in a country where there is an astonishing number of corruption. The post-research results aroused an intense concern about the subject and the need for strategies to deal with it. This is a bibliographic research with a qualitative approach and based on some theorists, in addition to some official sources.

Keywords: Citizenship. Corruption. Brazilian society.

\footnotetext{
${ }^{\mathrm{I}}$ Mestre em Ciências da Educação pela Absoulute Christian University, Pós- graduado em Supervisão Escolar pela Faculdade de Teologia Hokemãh - FATEH e Graduado em Normal Superior pela Universidade Estadual do Piauí - UESPI - E-mail: majebazorı@hotmail.com.
} 


\section{INTRODUÇÃO}

A palavra cidadania nos faz lembrar, a priori, de pessoas portadoras da educação e fiéis ao cumprimento dos seus deveres e direitos que lhes são exigidos e/ou garantidos na Constituição Brasileira. Ser cidadão significa ser súdito e soberano, e saber usar os seus direitos na intervenção das ações do Estado para, posteriormente, poder usufruir os serviços ofertados pelo mesmo, conforme a situação descrita na carta de Direitos da Organização das Nações Unidas - ONU (1948). O verdadeiro cidadão ama, respeita e luta pelo desenvolvimento de sua pátria. Sente-se no dever de protegê-la, agindo como verdadeiros leucócitos (células defensoras de um organismo). Segundo o sociólogo britânico T. H. Marshall (I893-198I), a cidadania moderna é um conjunto de direitos e obrigações que compreendem três grupos de direitos. Os direitos civis característicos do século XVIII; os direitos políticos, consagrados no século XIX e os direitos sociais do século XX. Essa teoria é particularmente aplicável nos processos de democratização do estado liberal em que um desses grupos de direitos tiveram sua predominância.

É evidente que a sociedade brasileira vive o pluralismo de valores, culturas, conhecimentos, raças, formas de agir etc., e que, de certa forma, o indivíduo termina influenciando-se com aqueles que estão ao seu redor, ocupando o mesmo lócus. A influência do meio é muito forte e, ao mesmo tempo, persuasiva. O indivíduo deixa, muitas vezes, de usufruir de sua própria concepção e termina agindo em conformidade com as concepções alheias. Para o sociólogo DURKHEIM (2010),

A organização dos homens em uma mesma sociedade, regulada pelas mesmas leis é o que permite a mediação de conflitos individuais e sociais: "A única força capaz de servir de moderadora para o egoísmo individual é a do grupo; a única que pode servir de moderadora para o egoísmo dos grupos é a de outro grupo que os englobe" (DURKHEIM, 2010, p. 428).

Obviamente, as dificuldades de construção e adequação da cidadania em conformidade com a fonte que lhe outorga, existem, uma vez que, se vive em um espaço onde a corrupção e os maus costumes vão ao desencontro das normativas constitucionais. A prática da cidadania no Brasil está, cada vez mais, se afunilando, onde os verdadeiros cidadãos e cidadãs sofrem à asfixia democrática por aqueles que praticam a corrupção.

O termo corrupção, segundo a Lei de Improbidade Administrativa, expressa atos de improbidade, desde aos danos ao erário, enriquecimento ilícito e violação aos princípios 
administrativos, ao tempo em que, o Código Penal a designa como ação do mau uso da função pública com o intuito de obtenção de vantagem indevida. É um fenômeno arcaico, mas que tem se intensificado nos últimos anos. Na concepção de NASCIMENTO (2016),

A corrupção é um fenômeno que tem atingido todas as sociedades, em menor ou maior escala. Os danos causados por ações corruptas, particularmente no setor público, têm gerado problemas que comprometem a sua própria capacidade administrativa, fazendo assim com que seu desempenho seja minimizado e se reflita, negativamente, em setores importantes da sociedade, como o econômico, o cultural, o social e o político (NASCIMENTO, 2016, p. 79-137).

A corrupção degenera a dignidade humana e propicia a desigualdade social, como um todo. Fere os princípios da cidadania, sufocando e obstruindo a sua civilidade. Ela pode apresentar-se em, pelo menos, duas maneiras: corrupção ativa e passiva. O Código Penal expressa o seguinte:

Art. 333 - Corrupção ativa é quando há o oferecimento de vantagem indevida a funcionário público, para determiná-lo a praticar, omitir ou retardar ato de ofício: Pena - reclusão, de 2 (dois) a ${ }_{2} 2$ (doze) anos, e multa. (Redação dada pela Lei no 10.763, de 12.11.2003).

Parágrafo único - A pena é aumentada de um terço, se, em razão da vantagem ou promessa, o funcionário retarda ou omite ato de ofício, ou o pratica infringindo dever funcional.

Art. 317 - Corrupção passiva acontece quando há solicitação ou recebimento para si ou para outrem, direta ou indiretamente, ainda que fora da função ou antes de assumi-la, mas em razão dela, vantagem indevida, ou aceitar promessa de tal vantagem: Pena - reclusão, de 2 (dois) a I2 (doze) anos, e multa. (Redação dada pela Lei no 10.763 , de 12.11.2003).

§ I o - A pena é aumentada de um terço, se, em consequência da vantagem ou promessa, o funcionário retarda ou deixa de praticar qualquer ato de ofício ou o pratica infringindo dever funcional (CÓDIGO PENAL - Lei 10.673/2003).

O principal Índice de Percepção da Corrupção - IPC, no setor público do mundo, vem avaliando pelo menos 180 países e territórios em uma escala de o à ıoo, onde o primeiro é considerado altamente corrupto e o segundo muito íntegro. O diagnóstico de 2019 mostra que o Brasil encontra-se no 106임 lugar em corrupção entre os países do mundo. Em relação à América do Sul, o resultado é também espantoso, pois este ocupa o $4^{\circ}$ lugar, conforme tabela, abaixo. 
Tabela or

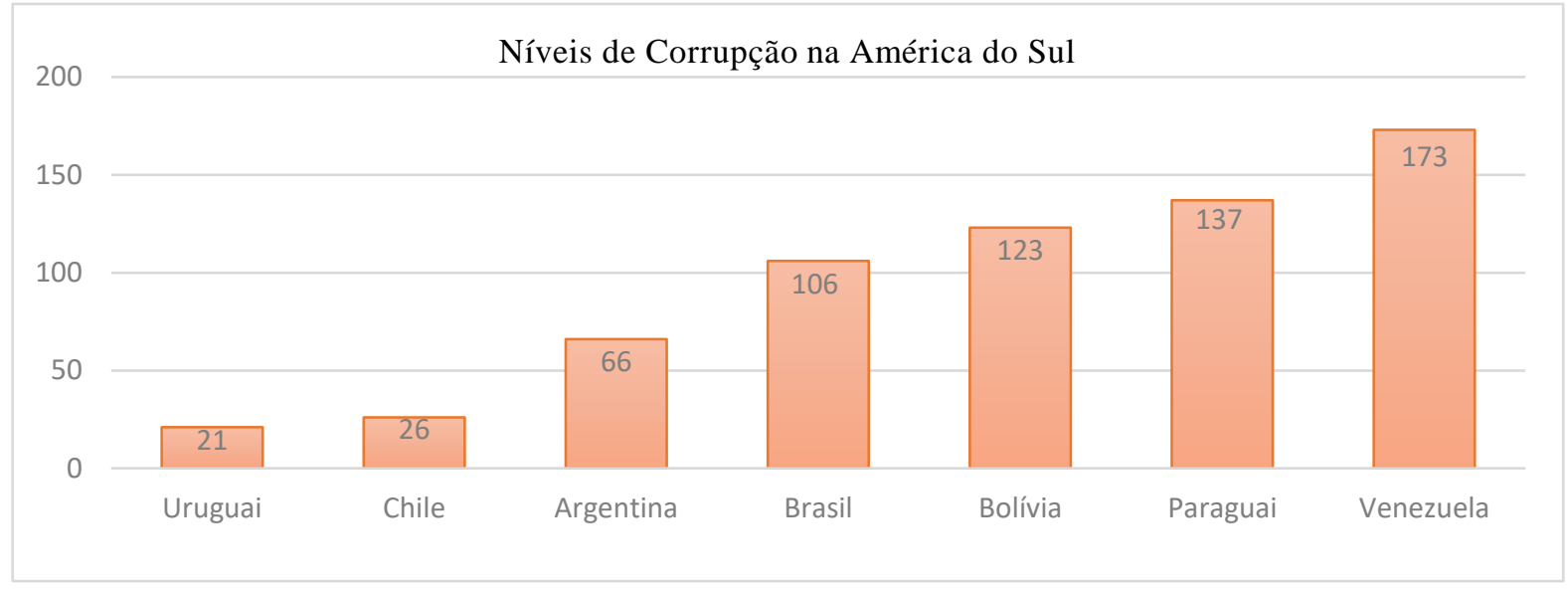

Fonte: Transparência Internacional

Os resultados apontam uma exorbitante escala de corrupção em meio à sociedade brasileira, onde os verdadeiros cidadãos sentem dificuldades para exercerem as suas cidadanias e cumprirem com as normativas expressas na Constituição Brasileira. Logo, cidadania e corrupção possuem trajetórias dicotômicas onde a primeira apresenta fidelidade às normativas constitucionais e a segunda simplesmente as ignoram. Essa situação proporciona, de certa forma, um sentimento de mal-estar e de revolta àqueles que procuram, a todo custo, exercer a sua cidadania em um país em que "tudo pode" e onde emprega-se o “jeitinho brasileiro” para alguém se dá bem.

\section{A CIDADANIA E SEUS EFEITOS}

A cidadania de uma pessoa, de um povo e/ou de uma nação tem valores imensuráveis na execução dos seus deveres e direitos no seio de seu país. Amparada no artigo 205 da C/F, a cidadania possibilita à presença, constante, dos valores morais, éticos, sociais e econômicos na vida da pessoa, desenvolvendo um espírito de patriotismo e solidariedade humana. $\mathrm{O}$ indivíduo que denota uma postura cidadã no meio social, proporciona admiração por todos aqueles que estão no seu entorno, além de ganhar confiança e credibilidade.

Todavia, as dificuldades de relacionamento dos cidadãos com grande parte de indivíduos que não demonstram preocupação, tampouco zelo com a prática da cidadania, é constante na sociedade brasileira. O cumprimento legal da cidadania, em um país corrupto é, muitas vezes, ignorado por aqueles que praticam a corrupção. A cultura corruptiva está se 
estendendo, progressivamente, e pode até apresentar-se nos pequenos negócios. O indivíduo que recebe um pequeno troco em seu favor e não o devolve, está cometendo uma suposta ação corruptiva.

Com efeito, a presença da postura cidadã é aplausível e cabível em qualquer lugar. Mesmo despercebida e/ou ignorada por aqueles que a descumprem, é admirada pelas pessoas que se enquadram na mesma linha de conduta. Quem pratica a cidadania tem a mente tranquila e orgulha-se de poder contribuir, honestamente, com o desenvolvimento social. $\mathrm{O}$ verdadeiro cidadão sabe respeitar os outros, em qualquer ambiente e não se equivoca ao requerer alguns direitos imprescindíveis à vida como educação, saúde alimentação moradia e etc. Demonstra revolta e inquietação quando toma conhecimento dos desvios ou da má empregabilidade dos recursos públicos que, uma vez bem empregados, poderiam atenuar os muitos problemas sociais do país.

A prática da cidadania denota amor, responsabilidade e compromisso que a pessoa tem para com o desenvolvimento de sua pátria. Para exercê-la é necessário conhecer os deveres e os direitos previstos na Constituição e estar convicto de que qualquer ação em desacordo com as normativas poderão afetar a sociedade.

$\mathrm{O}$ indivíduo que se preocupa de viver em acordo com as normativas dos estatutos desenvolvidos em uma comunidade, é considerado um autêntico cidadão. Sabe articular problemas, particular ou socialmente, e luta, incansavelmente, pelo desenvolvimento de seu território sem, no entanto, tirar proveito ou vantagem própria. Os efeitos da cidadania propiciam marcas dignas e inapagáveis na história da civilidade, sobretudo naqueles que apresentam fomentação pela honestidade e pela ética de um povo. Segundo DAUD (2016), apesar de estar fundamentada nos artigos, I, 5, 6 e I4 da Constituição Federal,

\footnotetext{
As desigualdades e os indicadores sociais não demonstram nenhum indício de que essa cidadania tutelada pela Constituição Federal está realmente sendo efetivada. O fato é que a organização do Estado, o corporativismo do poder político, bem como o não saber e o depender da população, limitam, quando não elidem totalmente, o exercício dessa cidadania (DAUD, 2016, p. 152-153).
}

Outrossim, fala-se tanto em cidadania em nosso país, no entanto pergunta-se: onde ela está? Um país que contribui para a construção da cidadania de seu povo não desvirtua o exercício do poder, não compactua com o mal uso do voto, não corrobora com políticas públicas excludentes, não contribui com a violência e nem se omite diante da fome, da 
nudez, da falta de saúde, de escola e de trabalho, e jamais aceitaria a falta de moradia decente e de segurança para o seu povo. A partir do momento em que se abstém dos direitos básicos do indivíduo, está-se obstruindo os seus horizontes de capacidades e negando-lhe a verdadeira cidadania.

\section{A ASFIXIA DA CIDADANIA EM MEIO À CORRUPÇÃO BRASILEIRA}

Em meio a expressiva porcentagem de corrupção que o nosso país apresenta, a cidadania brasileira sofre a asfixia democrática. O cidadão já não suporta mais vivenciar essa gama catastrófica, praticada por aqueles que fomentam a ganância, o poder e o menoscabo pelo outro. Diante disso, a sociedade clama por um firme compromisso, tanto da parte governamental, através de implementação de políticas públicas, quanto individual, com a impregnação da consciência, para que se possa resgatar à cidadania de milhões de indivíduos ora injustiçados e/ou excluídos dos direitos que lhes estão garantidos na Constituição Brasileira.

Notadamente, a corrupção no Brasil vem ganhando forças ao tempo em que incomoda os que se esforçam, para cumprirem com as suas cidadanias; exigem apenas o que têm por direito, pagam os mais altos impostos do planeta, votam livremente, declaram renda, participam de organizações (sindicatos e/ou associações e políticas), a fim de reivindicar melhorias para a sociedade, estudam com o objetivo de melhorar os seus conhecimentos e aperfeiçoar a qualificação para as atividades do exigente mercado.

O verdadeiro cidadão sente-se incomodado ao ter uma nota fiscal negada por um estabelecimento comercial; em assistir propagandas comerciais enganosas; tomar conhecimento de desvios do dinheiro público; de presenciar a mais torpe pobreza em meio a um país que detém a posse de uma riqueza colossal etc. Esses acontecimentos geram desconforto e proporcionam asfixia à democracia daqueles que apresentam fome e sede de justiça pela igualdade social. A corrupção brasileira passou a ser uma doença crônica que vem empecilhando a construção da cidadania e, consequentemente, encolhendo o desenvolvimento econômico, onde uns têm de menos, outros têm demais e outros nada têm. Ou seja, a riqueza está concentrada nas mãos de poucos, conforme amostra do gráfico, abaixo. 
Tabela 02

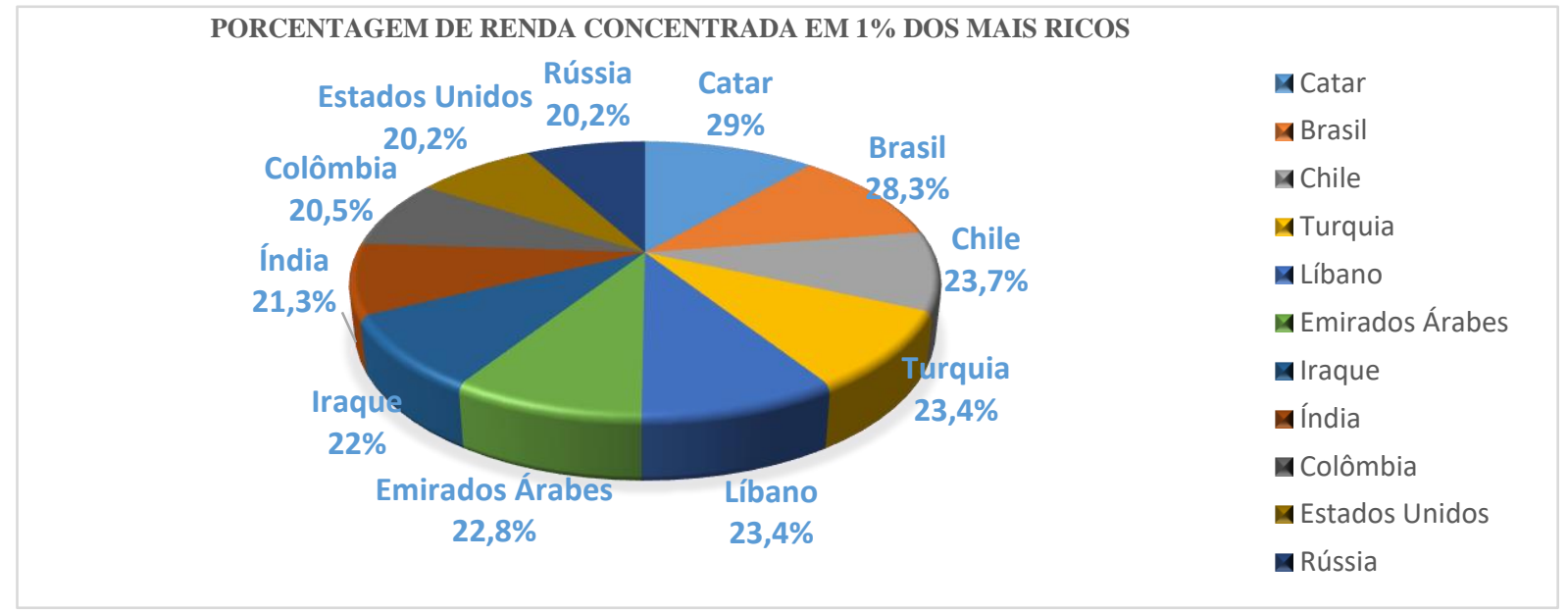

Fonte: Ranking de concentração de renda - Pnud/2019

O exposto explicita uma distribuição de renda heterogênea, onde o Brasil ocupa o segundo lugar, pois o I\% mais rico de sua população concentra $28,3 \%$ da renda do país, ficando atrás apenas do Catar, onde o $1 \%$ mais rico concentra $29 \%$ de sua renda. Não é à toa que $41,9 \%$ da renda brasileira concentra-se nos 10\% mais ricos do país. Sendo assim, conclui-se que a distribuição de renda brasileira é absolutamente desfavorável às necessidades de sua população. A heterogeneidade de renda em um país descaracteriza a cidadania de seu povo. A cidadania preza pelo crescimento econômico e social equilibrado, onde não haja volumosa discrepância de renda entre indivíduos de uma mesma sociedade.

Entende-se que as riquezas ilegais, sobretudo resultado da suposta sonegação de impostos, de desvios de dinheiro público, do tráfico de mercadorias, do estelionato, da prática de suborno, além de outros indícios, estão na contramão da legislação brasileira e agindo como autênticos poluidores da cidadania. O Brasil vivencia os dois lados da realidade: cidadania e corrupção, como afirma BOBBIO (1991),

Acontece muitas vezes de se falar do choque entre dois estados paralelos, em que, de um lado, está o plano ideal do "[...] ordenamento previsto pela constituição, em que as decisões coletivas devem ser tomadas pelos órgãos competentes, com delegação bem definida" e, do outro, “[...] se desenvolveu um novo ordenamento segundo o qual muitas decisões coletivas são tomadas diretamente pelos grupos interessados, mediante acordos fundamentados exclusivamente no reconhecimento do poder recíproco" (BOBBIO, I991, p. 70-7I).

A prática corruptiva fere os princípios sociais, dispostos na legislação, propiciando sérios agravamentos à sociedade. Ambas possuem caminhos totalmente díspares e objetivos 
contrários. O exercício da cidadania requer esforços e fidelidade às normativas constitucionais. Para CHRISTENSON (1974),

A cidadania solidária “é uma expressão da procura de justiça pelo homem, de seu interesse pelos oprimidos e de seu otimismo no sentido de que a razão e humanitarismo poderão levar e levarão a um mundo melhor" (CHRISTENSON et al. 1974, p. 337).

Mesmo diante da situação corrupta que o povo brasileiro enfrenta, nos últimos tempos, sobrevivem cidadãos fiéis às normativas constitucionais, reconhecem suas limitações, cumprem com suas obrigações civis ou naturais e exigem somente o que têm por direito. $\mathrm{O}$ indivíduo que apresenta essas qualidades dispõe de uma mente equilibrada, capaz de enfrentar qualquer obstáculo e superar qualquer consequência. Não se cansam, tampouco perdem as forças e/ou desfalecem os ânimos em busca de justiça social.

\section{FAMÍLIA E ESCOLA: UMA PARCERIA COM O PODER ATENUATIVO DE CORRUPÇÃO}

Por ser a família o primeiro grupo social em que o indivíduo faz parte, encontra-se incumbida em instruir os seus componentes a cumprirem com a lisura e com a exequência dos valores sociais. As primeiras lições de cidadania devem acontecer a partir das pequenas ações que acontecem no seio do lar. Se pegou emprestado, devolva. Se sujou, limpe. Se errou, peça desculpas. Se encontrou algo que se estava perdido, guarde-o para devolver ao verdadeiro dono. Se recebeu um troco errado em seu favor, devolva-o. É sabido que instruções educativas promovidas pela família irão facilitar à continuidade da formação escolar além de evitar problemas maiores no futuro.

A família que presencia o filho chegar em casa com alguma coisa (brinquedos, objetos diversos, dinheiro etc.), e não procura saber de onde veio e/ou onde encontrou, poderia estar compactuando com ações ilícitas e possibilitando a abertura de caminhos que dariam acesso à indignidade. Independentemente do valor, a apropriação ilícita de algo é corrupção. O filho que, a pedido do pai, for à padaria e ao chegar não devolver o troco estaria sinalizando indícios de corrupção, a não ser que o pai tenha autorizado a ficar com o que sobrou. Cabe, portanto, à família apregoar as primeiras lições de honestidade. São essas instruções que efetivarão a construção da verdadeira cidadania. De acordo com OLIVEIRA (2010), 
Escola e família agem como meios socializadores mesmo que sejam diferentes. Ambos organizam e preparam indivíduos para suas vidas, social, econômica e cultural. No entanto, apesar de a família e a escola serem os principais contextos de desenvolvimento humano, poucos estudos científicos têm-se dedicado a compreender de forma sistemática a relação existente entre ambas (OLIVEIRA, 2010, p. 99-108).

Quando a família assume com as primeiras tarefas que lhes estão incumbidas, no seio do lar, certamente a escola não terá tantas dificuldades na complementação educativa. Essa parceria é imprescindível entre ambas para o norteamento da formação do indivíduo. É extremamente imprescindível que haja o acompanhamento contínuo dos pais sobre as ações dos filhos, para possíveis correções. As ações de um filho e/ou aluno com indícios de desonestidade, por mínimas que sejam, quando não corrigidas, poderão propagarem-se gerando graves consequências no futuro, inclusive a prática corruptiva. Na concepção de SILVA (2019),

Tanto a família quanto a escola desempenham papéis decisivos na educação e formação da criança. Portanto, quando a educação dada no lar, pela família, acontece de forma satisfatória, fazendo o necessário para haver uma integração em parceria com a escola - a partir dessa parceria, a criança se torna um adulto capaz de contribuir positivamente para a construção de uma sociedade mais justa, ampla, mais valorizada (SILVA, 2019, p. 86-95).

Família e escola devem estar em sintonia, falando a mesma língua, compartilhando as mesmas intenções e lutando pelos mesmos ideais. Essa parceria, uma vez consolidada, contribuirá com o progresso de uma nação. O progresso de um povo reflete-se na prática da erudição, dos bons costumes e da honestidade.

Dependente, exclusivamente, de uma educação qualitativa, o progresso resulta na existência de uma sociedade menos corrupta e mais igualitária. No entanto, acredita-se, que o investimento precoce na educação (tanto na família quanto na escola e/ou na sociedade), seria a maneira mais eficaz para atenuar os expressivos números de corrupção no Brasil, uma vez que a educação é a principal chave desmascaradora da alienação e estimuladora pela busca das luzes do conhecimento.

\section{I CIDADANIA PRODUTO DA EDUCAÇÃO; CORRUPÇÃO PRODUTO DA INDECÊNCIA}

Há uma discrepância bastante acentuada entre as ações da cidadania e as da corrupção. As ações da cidadania apresentam um leque de benefícios sociais. $O$ verdadeiro 
cidadão esforça-se para cumprir com as normativas expressas na legislação vigente, mesmo que os obstáculos tentem impedir. Zela pelo patrimônio público e denuncia qualquer ato que não esteja em acordo com a lei. Demonstra grande apreço e respeito pelo próximo, apresentando uma empatia considerável. Por conhecer bem os seus limites possui uma notável facilidade de convivência social.

A corrupção, ao contrário da cidadania, propicia atos depreciadores às normativas constitucionais e atropela os princípios básicos que a constitui. Incorporado pela cupidez, o corrupto encontra-se sempre disposto a driblar os regulamentos de uma ordem. Os atos de corrupção são frequentes e acontecem em todas os setores sendo, mais ligeiramente observado, no âmbito da administração pública. Associados a comportamentos que ferem a lei, os atos de corrupção proporcionam a mais atrozes ilegalidades na estrutura social.

A sociedade brasileira apresenta-se incomodada com tantos atos de corrupção. Nosso país ocupa o 14 을 lugar com maior carga tributária, em relação aos países do mundo, mas que apresenta a pior posição entre os 30 países analisados no que diz respeito ao retorno dos valores arrecadados em prol do bem-estar social, deixando assim os cidadãos brasileiros, completamente, insatisfeitos

\section{CONSIDERAÇÕES FINAIS}

Mesmo diante da atual situação constrangedora em que a sociedade brasileira vive, acredita-se que a partir do momento em que houver a efetiva parceria entre família/escola, esse problema tende a ser atenuado, considerando serem elas as principais responsáveis pela consolidação da cidadania de um povo. A sociedade brasileira está composta por um mesclado de cidadãos e corruptos onde os primeiros, analogicamente, sufocados pela indecência, apresentam certas dificuldades de convívio social. Esses, esforçam-se pelo cumprimento das diretrizes constitucionais, zelam pela sua pátria e contribuem para o seu desenvolvimento.

Todavia, defende-se que haja maiores investimentos no setor educacional para que se possa combater ou, pelo menos, amenizar a corrupção brasileira. A atenuação desse suplício promoverá o crescimento econômico, a geração de empregos decentes, melhor distribuição de renda, encolhimento das desigualdades sociais e, consequentemente, a robustez do estado de direito. Diante dos mais ríspidos atos de corrupção em nosso país, 
surge a impressão de que a educação brasileira está sendo irradiada de forma implícita, uma vez que a prática mais robusta da corrupção vem sendo proporcionada por indivíduos que possuem formação acadêmica e, na maioria das vezes, possuidores de grandes bens.

Os verdadeiros cidadãos apresentam fome e sede de justiça pelas causas sociais e jamais concordariam com atos deploráveis, onde uns tiram proveito e outros ficam desprovidos do que tem por direito. A sociedade cidadã brasileira arca com tudo o que é exigido pelo Estado, no entanto, conduz em seus próprios ombros, as insuportáveis consequências geradas pela corrupção. Não é à toa que os verdadeiros cidadãos brasileiros vivem sufocados em meio a uma turbulência anticívica. Por viver em meio as incertezas da verdadeira "Pátria Amada Brasil," a cidadania sinaliza o enfraquecimento do seu cumprimento.

No entanto, há uma necessidade óbvia da correlação entre família-escola-sociedade, em refletir sobre o passado, preparar melhor o presente para o norteamento do futuro educacional com o objetivo de atenuação dos gravíssimos problemas de corrupção em nosso país. Acredita-se que educação é o único e exclusivo caminho que poderia realmente oferecer as alternativas que o nosso país precisa para a consolidação de uma sociedade mais justa e igualitária.

\section{REFERÊNCIAS}

BOBBIO, Norberto. Três ensaios sobre a democracia. Tradução de Sergio Bath. São Paulo: Cardim Alario, I991.

BRASIL, Constituição 1988. Constituição da República Federativa do Brasil. Senado, I988.

BRASIL- Lei no 10.763 , de 12 de Novembro. Corrupção Passiva e Ativa. Diário Oficial da União - Seção I - 13/II/2003.

CHRISTENSON, Reo M. et al. Ideologias e política moderna. Tradução de Aydano Arruda. São Paulo: IBRASA, 1974 .

Códigos - Decreto-Lei no 2.848, de 7 de dezembro de 1940 - Código Penal - Rio de Janeiro, 7 de dezembro de I940; $119^{\circ}$ da Independência e 52을 da República.

Direitos da Organização das Nações Unidas - ONU (1948). 
DUAD, Carvalho Rabelo - A atualidade da teoria de Thomas Humphrey Marshall: efetividade da cidadania, políticas públicas e limites do controle judicial - Revista de Direitos Sociais e Políticas Públicas | e-ISSN: 2525-988I| Brasília | v. 2 | n. I | p. I46 - I67 | Jan/Jun. 2016.

DURKHEIM, E. Da divisão do trabalho social. Martins Fontes, São Paulo, 2010.

Instituto Brasileiro de Planejamento Tributário - IBPT/2019.

Índice de Percepção da Corrupção - $\quad$ IPC https://www.transparenciainternacional.org.br/2019

Marshall, T. H. Citizenship and Social Class. In: MARSHALL, T. H. e BOTTOMORE, Tom. Citizenship and Social Class. Chicago: Pluto Classic(reimpr.), I996, p. 3-5I.

NASCIMENTO, Melillo Dinis do. O controle da corrupção no Brasil e a Lei no 12.846/2013 - Lei Anticorrupção. Revista Brasileira de Direito Municipal - RBDM, Belo Horizonte, ano 17, n. 6o, p. 79-137, abr./jun. 2016.

OLIVEIRA, Cynthia Bisinoto Evangelista de and MARINHO-ARAUJO, Claisy Maria. A relação família-escola: intersecções e desafios. Estud. psicol. (Campinas) [online]. 2010, vol.27, n.I, pp.99-io8. ISSN I66X. https://doi.org/10.1590/Soro3166X201000o100oi2.

Ranking de concentração de renda - Pnud 2019 - Foto: Infografia: Juliane Souza e Rodrigo Sanches/Gi

SILVA, Cristiane Rosana da. A importância da parceria da família e a escola na educação infantil. Revista Científica Multidisciplinar Núcleo do Conhecimento. Ano 04, Ed. o7, Vol. 09, pp. 86-95. Julho de 2019. ISSN: 2448-0959. Link de Acesso: https://www.nucleodoconhecimento.com.br/educacao/familia-e-a-escola, DOI: I0.32749/nucleodoconhecimento.com.br/educacao/familia-e-a-escola 